\title{
A CONQUISTA DO GOSTO DO PÚBLICO LEITOR: LEITORES PORTUGUESES DE PROSA DE FICÇÃO (1768-1820)
}

\section{CONQUERING THE READING PUBLIC'S TASTE: PORTUGUESE READERS OF PROSE FICTION (1768- 1820)}

\author{
Simone Cristina Mendonça*
}

Resumo: O estudo da imprensa periódica portuguesa nas primeiras décadas do século XIX revela o aparecimento de jornais e revistas que foram criados com o intuito de divulgar informação e cultura, mescladas com textos de leitura leve, como as histórias ficcionais. Interessante é notar que, mesmo nos primeiros anos do século, os leitores portugueses já se deparavam com contos ou novelas seriadas, que proporcionavam recreio em meio aos textos sérios, como os de conhecimentos científicos. A novidade nos faz pensar no processo de formação de um leitor específico em Portugal, o da prosa de ficção, que ascendia no país desde o setecentos. A formação do gosto do público leitor, a aliança entre histórias de ficção e periódicos e o comprovado sucesso da mesma são questões que permeiam este artigo, que apresenta resultados parciais de pesquisa de pós-doutorado, realizada junto ao Programa de Pós-graduação em Letras, do Ibilce/Unesp.

Palavras-chave: Leitor. Imprensa periódica. Prosa de ficção.

AвSTRACT: The study of the Portuguese periodical press in the first decades of the XIXth century reveals the emergence of newspapers and magazines that were created in order to disseminate information and culture, mixed with other texts, such as fictional stories. It is interesting to observe that even in the early years of the century; the Portuguese readers could find serial tales or novels among serious texts, such as those of scientific knowledge. It makes us think about the formation process of the readers in Portugal, mainly those readers who liked prose fiction, a genre that had been growing in the country since the eighteenth century. The formation of the reading public's taste the alliance between fiction stories and journals and their success are questions that permeate this article, which presents previous results of post-doctoral research, conducted at the Programa de Pós-graduação em Letras/ Ibilce / Unesp.

KEYwords: Reader. Periodical press. Prose fiction.

\footnotetext{
"Professora de Estudos Literários da Unifesspa - Universidade Federal do Sul e Sudeste do Pará, Doutorado em Teoria e História Literária (2007) pela Unicamp - bolsista do programa PDEE/CAPES, estágio de Pós-Doutorado na Unesp - campus de São José do Rio Preto, sob supervisão da Profa. Dra. Lúcia Granja. Email: simonecm@unifesspa.edu.br
} 
A história da imprensa em Portugal e em suas colônias vem de longa data, acompanhando de perto a invenção de Gutenberg, em 1445. Laurence Hallewell (1985, pp. 8-9) aponta, por exemplo, a existência de tipos móveis em colônias portuguesas na Ásia e na África ainda no século XV, levados por missionários jesuítas. É fato, no entanto, que as atividades tipográficas de Portugal e dependências sempre estiveram sob a rigorosa supervisão da censura ${ }^{1}$.

Apesar do controle dos impressos, a autora portuguesa Lúcia Maria Mariano Veloso verificou que, a partir da década de 50 do setecentos, houve um impulso na impressão de periódicos:

\footnotetext{
${ }^{1}$ Sobre a atividade de censura em Portugal e na América Portuguesa, consultar: ABREU, Márcia. "Censura e crítica: reações de um professor de retórica e poética à leitura de um romance”. in: Revista Brasileira de Literatura Comparada. Rio de Janeiro: Associação Brasileira de Literatura Comparada - Abralic - n. 8, 2006. pp. 113-128; ABREU, Márcia. "Em busca do leitor: estudo dos registros de leitura de censores". In: ABREU, Márcia \& SCHAPOCHNIK, Nelson (org.) Cultura letrada no Brasil: objetos e práticas. Campinas: Mercado de Letras/ALB/FAPESP, 2005; ALGRANTI, Leila Mezan. Livros de devoção, atos de censura: ensaios de história do livro e da leitura na América portuguesa (1750-1821). São Paulo: Hucitec, 2004; NEVES, Lúcia Bastos Pereira das. \& FERREIRA, Tânia Maria T. Bessone da C., "O medo dos 'abomináveis princípios franceses': a censura dos livros nos inícios do século XIX no Brasil" in Acervo Revista do Arquivo Nacional, Rio de Janeiro, 4 (1), pp. 113-119, 1989; NEVES, Lúcia Bastos Pereira das. "Um silêncio perverso: censura, repressão e o esboço de uma primeira esfera pública de poder (1820-1823)" in CARNEIRO, Maria Luiza Tucci (org.). Minorias Silenciadas: História da Censura no Brasil. São Paulo, SP: Editora da Universidade de São Paulo / Imprensa Oficial do Estado / FAPESP, 2002; VILLALTA, Luiz Carlos. Reformismo Ilustrado, Censura e Práticas de Leitura; usos do livro na América Portuguesa. São Paulo: [s.n.], 1999. Tese (doutorado) - Universidade Estadual de São Paulo, Faculdade de Filosofia, Letras e Ciências Humanas; VILLALTA, Luiz Carlos. "Censura literária e inventividade dos leitores no Brasil Colonial” in CARNEIRO, Maria Luiza Tucci (org.)., 2002. Op. cit.
}

O primeiro número assinalável de publicações (1751-1760) verifica-se no reinado de D. José, cujo desenvolvimento económico e cultural se deve ao Marquês de Pombal, havendo a referir jornais de entretenimento cultural como 'O Anonimo', publicações ligadas à previsão do tempo e à astrologia, antepassados dos almanaques [...] (VELOSO, 1987, pp. 30-1).

A Impressão Régia de Lisboa, fundada em 1768 sob as ordens do rei D. José I, em muito contribuiria com o desenvolvimento cultural citado. Seguindo uma tendência de importantes avanços na produção editorial portuguesa, tais como a abertura da oficina de gravura de João Villeneuve, em 1733, e a assinatura do decreto de autorização de admissão de tipo e material gráfico livre de direitos (Cf. ARAÚJO \& MENDES, 1914), a casa impressora oficial do reino participava de um contexto reformista, do qual faziam parte a Junta do Comércio (1756), o Erário Régio (1760), a Real Mesa Censória (1768) e a Junta de Providência Literária (1772).

Os pesquisadores Norberto Araújo e Artur Pareira Mendes consideraram que

(...) foi a necessidade instante de dar a conhecer ao povo as obras dos clássicos, que os impressores de então quási monopolizavam e vendiam por elevados preços, um dos factores mais preponderantes para a fundação do estabelecimento gráfico do Estado, mas teve tembêm [sic] grande influência, é certo, a necessidade de fazer ingressar num estabelecimento próprio os trabalhos do tesouro, já então bastante rendosos para os industriais, e que andavam dispersos por diversas 
oficinas graficas privilegiadas, das quais os proprietarios conservavam o título de impressores régios (ARAUJO \& MENDES, 1914, p. 22).

Além dos locais de venda de livros existentes em Lisboa no período da fundação da Impressão Régia, o escoamento de sua produção contava com uma Loge da Impressão Régia, situada na Real Praça do Comércio. Seu catálogo de "livros que se vendem por justos preços”, elaborado pelo administrador Francisco de Paula da Arrabida, em 1771, listava cerca de 5.000 títulos entre a produção própria e os livros importados (Cf. GUEDES, 1987, p. 82). No decreto de fundação da Loge, de 07 de Abril de 1769, D. José I incentivava a importação de livros europeus de outras tipografias, bem como a exportação dos produzidos na Impressão Régia, "sendo este [o intercambio com as Praças da Europa] o meyo mais eficaz para os Livros da sobredita Imprefsão Regia terem mais fácil consumo, e se fazerem mais conhecidas na Europa as Obras portuguesas" (PORTUGAL, 1769, p. 8 apud SOUZA, 2007, p. 23) 2.

Com relação à importação de obras do estrangeiro, incentivadas por sua majestade como meio de estimular a exportação das produções da Impressão Régia, merece realce a estratégia dos anúncios dos livros europeus recém-publicados nos periódicos em circulação no setecentos. Ernesto Rodrigues, ao traçar estudo sobre Literatura e jornalismo em Portugal, conforme subtítulo de seu livro, destacou o periódico setecentista Gazeta Literaria, que trazia os lançamentos de livros

\footnotetext{
${ }^{2}$ Serão mantidas a ortografia e a pontuação das fontes
} primárias. na Europa, divulgando as publicações científicas ou literárias, de história e política:

Esta Gazeta Literaria/ou/Noticia Exacta
dos Principaes/escriptos, que modernamen-
te se vão publicando na Europa//Conforme
a Analysis, que delles fazem os melhores
Criticos, /e Diaristas das naçoens mais civi-
lizadas [1761] é o primeiro esforço sério
para nos colocar a par da bibliografia
europeia. (RODRIGUES, 1998, p. 91)

Além dos anúncios de obras importadas, era possível encontrar ofertas de publicações nacionais. A título de exemplo, citamos a Gazeta de Lisboa, jornal em que foram anunciados títulos em prosa de ficção em período próximo, como "Escolha das melhores novellas, e Contos Moraes: escritos em Francez por Mrs. D'Arnaud, Marmontel, Madame Gomes, e outros: e traduzidos em Portuguez, obra util para os que desejão recrear-se, e instruir-se á hum tempo.” (em 29 de Junho de 1784) e "Aventuras de Telemaco, traduzidas pelo Bacharel Jofé Manoel Rodrigues Pereira, Traductor das Noites de Young: nova edição correcta, emendada, e ornada d'huma estampa fina" (em 24 de Dezembro de 1784, Cf. SOUZA, 2007, p. 26).

Quanto à produção editorial da Impressão Régia de Lisboa, particularmente no que diz respeito às obras em prosa de ficção, verifica-se a publicação de grande número de títulos, ainda no séc. XVIII. Como analisa Pedro Canavarro, encomendas de particulares revelam que a Impressão Régia funcionava como uma oficina tipográfica, em que "também o romance de ambiente burguês ou plebeu, proveniente de Inglaterra, e verdadeira novidade da época, nos aparece sob a forma de encomenda para Pamela, de 
Richardson (publicado pela primeira vez em 1740), e Tom Jones, de Fielding (cuja 1. ${ }^{a}$ edição datava de 1749)" (CANAVARRO, 1975, p. 60).

No século vindouro, as publicações em prosa de fiç̧ão da casa impressora oficial do reino continuaram a serem feitas, atingindo, apenas nas duas primeiras décadas do oitocentos, o somatório de 16 obras, conforme atestam os livros de Registo de $\mathrm{Obras}^{3}$, conservados na Imprensa Nacional Casa da Moeda, em Lisboa. As informações contábeis presentes nesses livros (como nomes das pessoas que solicitavam a impressão, título, número de exemplares, valores e datas dos lançamentos financeiros) nos fazem pensar em um interesse dos portugueses em imprimir contos, novelas, aventuras e histórias, possivelmente visando o comércio dos mesmos.

Além das publicações feitas na Impressão Régia de Lisboa, verifica-se que outras novelas, outros contos e romances traduzidos eram impressos em tipografias diversas e, assim, também circulavam em Portugal desde o setecentos, e incentivavam a produção literária local, feita por portugueses que ainda não se arriscavam a assumir a autoria de suas obras, como contextualiza José Tengarrinha:

Uma das obras que nos princípios do século fizeram maior furor, tendo

\footnotetext{
${ }^{3}$ Ressaltamos que o Arquivo da Imprensa Nacional Casa da Moeda de Lisboa, se encontra no prédio da Casa da Moeda, onde o acesso é restrito. Agradeço à Dra. Margarida Ortigão Ramos pela permissão de entrada. Para mais informações sobre a publicação de prosa de ficção pela Impressão Régia de Lisboa, consultar: SOUZA, Simone Cristina Mendonça de. Primeiras impressões: romances publicados pela Impressão Régia do Rio de Janeiro (1808-1822). Campinas, SP: [s.n.], 2007. Tese (doutorado) - Universidade Estadual de Campinas, Instituto de Estudos da Linguagem.
}

sido sucessivamente reeditada (pelo menos 8 vezes), foi a melodramática História da virtuosa e infeliz Clara Harlow, de Richardson. Outros traduzidos do inglês, como esta, e do francês, assim como de autores portugueses que em geral se mantinham no anonimato ou assinavam apenas com as iniciais, aparecem em número muito elevado. Pelos títulos de algumas delas é fácil depreender a sua natureza: A desgraçada morte de três amantes (1787), História do amante liberal (1788), Os amantes desgraçados (1790), A inocência triunfante pelos extremos do amor (1791), Florinda ou o sonho verificado (1816), A experiência amorosa (1817) (TENGARRINHA, 1989, p. 56).

O gradativo aumento no número de livros ou folhetos que traziam histórias ficcionais entre a segunda metade do século XVIIII e os primeiros anos do século XIX aponta para uma conquista do gosto leitor da época que, aos poucos, deparava-se com um título anunciado nos jornais, um livro a venda no catálogo da citada Loge, por exemplo, um exemplar nas prateleiras de livrarias do Rossio ou "ao terreiro do Paço", onde ficava a Loja da Gazeta (conforme foi anunciado em 26/01/1802).

Ademais o crescimento da produção do gênero ficcional em Portugal seguia um progresso que também se dava na produção periódica, como analisa Lúcia Maria Mariana Veloso, lembrando em nota que "Os jornais exigiam a concessão de alvarás que eram retirados por conveniência do governo. A 
censura prévia era uma das exigências na concessão de alvará"4:

Na década de 1801 a 1810 verificou-se aquilo que podemos chamar uma explosão jornalística. Apesar do período de instabilidade política provocada pela guerra entre a Inglaterra e a França de que resultou a invasão francesa, a economia e a cultura, cujos fundamentos foram lançados no período anterior, continuaram prósperas, mercê do dinamismo das estruturas tanto económicas como culturais. A fundação de fábricas, algumas no ano de 1802, e a criação de novas escolas, nomeadamente de ensino agrícola, artístico e militar, demonstram a resistência que essas estruturas ofereciam às dificuldades criadas pela instabilidade política. Em relação ao desenvolvimento jornalístico, além da introdução de novas técnicas no fabrico do papel que passou a utilizar fibras vegetais, é importante assinalar que o jornal surge como uma necessidade de informação corrente. Aparecem os primeiros jornais diários ('Diário Lisbonense', 'Gazeta de Lisboa' e o 'Mensageiro'), influência também dos jornais estrangeiros, sobretudo 'Le Moniteur', muito lido entre nós (VELOSO, 1987, pp. 31-32).

A Impressão Régia de Lisboa não ficou de fora dessa "explosão" e também ocupou seus prelos com a publicação de periódicos

\footnotetext{
${ }^{4} \mathrm{~A}$ título de informação, vale saber que a liberdade de imprensa, em teoria conquistada na Constituição de 1821, foi revogada por D. João VI, em 1824. Em 1828, o regime absolutista de D. Miguel impôs maior censura aos periódicos, que somente reconquistaram a liberdade de imprensa em 1834, com o país sob as ordens de D. Maria II. (Cf. SANT'ANNA, 2007, pp. 17-23).
}

nos primeiros anos do oitocentos. O objetivo de contribuir para divulgação das ciências e a instrução dos portugueses não se ateve, então, à publicação de livros. Quanto aos periódicos nascidos na tipografia real, mereceram destaque no estudo Mágico folhetim, de Ernesto Rodrigues, O Redactor, ou Ensaios Periódicos de Litteratura, e Conhecimentos Scientíficos Destinados Para Illustrar A Nação Portugueza, publicado em 1803; e Analecto de Recreação e erudição, também editado na Impressão Regia, em 1805, "Por Ordem Superior":

O Redactor e o Analecto visam, no gosto pela leitura, a educação literária junto da mocidade, sendo condição necessária voltar aos clássicos e a estudos sobre o idioma. Nestes títulos pilares de era há pouco revoluta, e ainda aquém ou distraídos da litografia (1798; a gravura sobre aço é de 1792, as primeiras em matriz de aço para ilustração de livros só em 1810 - artes sem as quais o Romantismo seria diferente), podíamos assentar a estratégia do revistismo literário. (RODRIGUES, 1998, p. 110).

Em relação a este último, por meio de consulta ao exemplar do primeiro número, alocado na Biblioteca Nacional de Portugal (cota: P.P.7314 P), verificamos logo em suas primeiras páginas a presença de um texto em prosa de ficção intitulado "Modo de ressucitar os mortos. Conto persiano", impresso desde a página 5 até à página 16. As onze páginas de conto se sobressaem àquelas dedicadas aos demais textos presentes no periódico, que ocupam entre um e cinco lados das folhas, como, por exemplo: "Memoravel providencia 
economica do Senhor Rei D. João II. contra os monopolistas do trigo" (pp. 16-18); "O throno. Anedocta oriental" (pp. 39-40); "Principios da Filosofia Moral dos Peripateticos” (pp. 40-46); "O erro. Fabula" (p. 47); "Decisão prudente, e artificiosa de huma acção criminal injusta” (pp. 47-48).

Já a folha mensal O Redactor ${ }^{5}$, possivelmente de fácil acesso aos consumidores, tendo em vista que, segundo citação encontrada em seu cabeçalho, era vendida em Lisboa "nas lojas de todos os livreiros, e na da Gazeta; assim como nas principaes do Reino", verificamos maior número de narrativas ficcionais. No número I, de setembro de 1803, lemos na página 22 um conto com personagens orientais de curioso título: "Hal-mehi-Catimira", que é seguido pelo ensaio científico "Arranjo sistemico das differentes Sciencias pertencenter á Philosophia Natural", na página 28.

Os números seguintes nos trazem uma prosa de ficção seriada: em outubro de 1803 iniciou-se a publicação de "Hum conto Suisso" (p. 57), que teve prosseguimento no mês seguinte, com a seguinte indicação no sumário: "Hum Conto Suisso continuado desde paginas 61...99". Vale lembrar que no mesmo número III nos deparamos com "Noticia Historica de Athenas, etc. Continuada desde paginas 54...91".

De acordo com Rodrigues (1998, p. 209), as primeiras publicações em capítulos de narrativas de ficção em Portugal são de data ainda anterior ao caso citado acima, mais precisamente, de 1802 , quando se estréia o término do texto com a fórmula "Continuarse-ha”, no periódico Novidades Literárias. Rege

${ }^{5}$ Biblioteca Nacional de Portugal. Cota: J 1306 B. a interrupção do texto, entretanto, o espaço disponível na página e não o conteúdo da história e o aguçamento do interesse dos leitores por sua continuação.

O mesmo autor alerta para o uso duvidoso do adjetivo "literário" nos títulos das folhas, uma vez que este poderia ser usado como artifício para que os editores escapassem da censura:

Antes de avançar, notemos que muitas designações 'literárias' ou programas 'científicos' de certas publicações eram a melhor maneira de esquivar ameaças futuras, quando rebeliões (e foram tantas nos anos 40) chamavam ao Ministério do Reino poderes descricionários, com censura ou suspensão dos jornais, onde se exceptuavam os literários e científicos e os diários das Câmaras legislativas e do Governo. (RODRIGUES, 1998, p. 101)

A pesquisadora Benedita Sant'Anna notou em sua tese que, entre 1779 e 1820 , "a imprensa especializada em literatura, conhecimentos diversos e instrução assume um papel predominante em Portugal" e que os periódicos "divulgadores de conhecimento, de arte e das técnicas (...) não sucumbiam com as restrições impostas ao jornalismo político que estava fortemente limitado por severa censura prévia (...)" (SANT'ANNA, 2007, p. 38).

Possivelmente para esquivar-se das malhas da censura, os autores dos textos considerados como literários publicados nas folhas periódicas, também não costumavam identificar-se. Não obstante, encontramos um exemplo significativo de texto narrativo que não veio publicado anonimamente, no 
periódico Bibliotheca Universal extrahida de muitos jornaes, e das obras dos melhores escritores Antigos, e modernos, ele próprio anunciado como escrito "Pelo author das Viagens de Altina" (Luís Caetano de Campos), em 1803.

No segundo número da Bibliotheca (de fevereiro de 1804), o leitor conheceu a longa história de "Carite, e Polydoro", por meio do "Romance, de João Jaques Barthelemy" (pp. 3-51), que se encerrava com "Continuar-sehá". O restante do romance veio, de fato, no mês e número seguintes, com o "Artigo II'. Continuação do Romance Carite, e Polydoro" (pp. 30-92), quando há o informe: "fim do Romance de Carite, e Polydoro".

As narrativas podiam, destarte, vir precedidas de uma classificação, atribuída pelos termos "conto", "romance" ou "novela” e, como se vê, às vezes vinham divididas em duas ou três partes. Assim aconteceu, por exemplo, com "Iddalina de Tokenbourg, Historia alemã”, que, em 1802, ocupou 35 páginas do número XIV do periódico Variedades, além de 28 e 26 páginas, respectivamente, nos dois números posteriores. Nesses casos de retomadas, também foi verificado o uso das expressões "continuar-se-há", ao final de um texto e "continuação de..." no início do número seguinte do periódico.

Entretanto, nem sempre é fácil distinguir se o texto anunciado no sumário é, de fato, um conto, um texto ficcional, ou se se tratava apenas de uma notícia contada de forma romanceada, deixando margem para se questionar sua veracidade. $O$ problema se torna maior quando nos lembramos de que nesta época a ficção também era contada como fato acontecido ${ }^{6}$. Os próprios títulos de alguns contos elencados nos sumários dos periódicos, às vezes, enganam, como o de "Julia, Historia verdadeira", texto ficcional epistolar, também publicado em Variedades, em 1802.

Para definir quais são os textos em prosa de ficção se faz necessário recorrer a algumas particularidades dos títulos, que podem ser nomes próprios, na maioria dos casos, femininos; apresentar palavras relacionadas a casais apaixonados, à virtude ou à amizade; trazer uma certa classificação pressuposta pelos termos "conto", "história", "aventuras", "romance" ou "novela"; e, geralmente, contar com um subtítulo, precedido pela conjunção "ou".

A certeza da definição do gênero, destarte, se torna mais difícil de ser alcançada, pois, como se viu, os contos, romances e novelas eram publicados em meio a textos de interesses variados, como de política, de novidades científicas e de notícias sobre os acontecimentos da época, numa miscelânea de divertimento e instrução. Veja-se o caso de Divertimento instructivo ou collecção escolhida de novellas, historias, contos moraes, anedoctas interessantes, parabolas, fabulas, ditos filosoficos, contos para rir, \&c. que dos prelos da Impressão

\footnotetext{
${ }^{6}$ Márcia Abreu, investigando os discursos dos censores responsáveis por analisar romances e autorizar ou não sua publicação, verificou que uma das críticas devia-se ao fato de que os leitores poderiam tomar os textos ficcionais como histórias verdadeiras, criando-se uma perigosa ilusão de verdade e, ainda, com a possibilidade de se corromperem os textos históricos (Cf. ABREU, 2003, pp. 272-299). Já Sandra Vasconcelos trouxe, entre outros exemplos, o de Samuel Richardson, que se declarou depositário de um conjunto de cartas, editadas para publicação de seu romance (Cf. VASCONCELOS, 2002, pp. 92-95).
} 
Régia de Lisboa, saiu a partir de 1804. Esse periódico trazia em seu frontispício a apresentação: "obra moral, instructiva, e agradavel destinada para honesto divertimento, $\mathrm{e}$ util instrucção da mocidade Portugueza" e, no conteúdo do número II, logo após uma estampa colorida, apresentava "Os esposos reconhecidos ou o triunfo da virtude. Novella sentimental imitada do alemão" (pp. 35-50). Nesse mesmo número, a mocidade portuguesa poderia ficar à par da história "Do curso ordinário do mundo" (pp. 56-58), atualizar-se com a "Noticia de invenções antigas e modernas" (pp. 60-61) e terminar sua leitura com "Pensamentos diversos" (pp. 62-64).

José Tengarinha comenta o desenvolvimento da imprensa periódica portuguesa ressaltando o grande número de publicações chamadas "de pendor sentimental", ao relembrar que era nos "folhetos, fascículos ou cadernos (normalmente mensais)" que se imprimia essas "obras de menor mérito e, por isso esquecidas, [que] constituem no entanto uma vasta massa de produção literária que é um pano de fundo indispensável para a compreensão do gosto e da sensibilidade do público, bem como do aparecimento de obras de maior valia" (TENGARRINHA, 1989, p. 56). Segundo o autor, essas publicações

Denunciam uma tendência pré-romântica (exageros sentimentais e melodramáticos, individualismo, desequilíbrios estruturais e estilísticos da obra, desapego aos cânones e valores clássicos) que coexiste com a tradição clássica e ainda está longe de afirmar uma teoria própria. Podem considerar-se a emergência de novas formas de sensibilidade, de novos quadros psicológicos que vieram sendo preparados muito longa e lentamente, mas que só agora aparecem sob a forma de ruptura. (TENGARRINHA, 1989, p. 56)

A temática dessas obras, publicadas muitas vezes nos periódicos, gira em torno do amor e dos obstáculos que os amantes encontravam para realiza-lo, tais como impedimentos familiares, casamentos arranjados que separavam amores da juventude, diferenças de classe social e, mesmo, guerras, em histórias geralmente traduzidas ou ainda escritas por portugueses anônimos ou que se identificavam apenas por iniciais.

$\mathrm{Na}$ estrutura das narrativas encontramos protagonistas que geralmente pertenciam à nobreza, personagens secundários que se colocavam como servos fiéis ou até confidentes, ambientes internos em que se destacam objetos luxuosos, enredos injetados de grandes sofrimentos das personagens, sobretudo das femininas, mortes e assassinatos previamente anunciados.

O tema do amor não se limita a aparecer apenas nas narrativas ficcionais, como nas publicadas no corpo dos jornais, eclodindo também fora da prosa de ficção, nos manuais de conquista, "como se de repente, e só então, o amor sentimento e o amor-prazer nas suas mais simples manifestações tivessem sido descobertos por amplos grupos sociais e pudessem ser tratados livremente em público." (TENGARRINHA, 1989, p. 57).

Assunto facilmente relacionado ao universo das mulheres, o amor também pode ter sido chamariz para crescimento do público leitor feminino em Portugal, que logo passou a ter à disposição periódicos específicos, 
como O correio das modas, cuja "Introducção" ao primeiro número anuncia:

Cada Folheto constará de duas Estampas illuminadas, e de dezesseis Paginas de Impressão. Nas primeiras virá a explicação das Figuras, e as reflexões sobre o estado da Moda, e nas outras huma collecção de Contos, Anedoctas, e Ditos Sentenciosos, com o titulo de Entretenimento de hum quarto de hora. As outo Figuras dos dous primeiros Folhetos, pertencem á Moda do Inverno, e Primavera deste anno, nos que formos publicando de pois destes, daremos as que se forem succedendo em París, Londres, e Lisboa [...]. (O correio das modas, 1807, p. 5-6)

Note-se que, entre estampas de vestimentas, como se pode deduzir pelas explicações, e comentários sobre as tendências da moda da estação, inclusive no exterior, vinham publicados contos, destinados ao "Entretenimento de hum quarto de hora". Em consulta realizada ao exemplar disponível na Biblioteca Nacional de Portugal (cota: L. 6609 I P), que contém quatro folhetos, surpreendeu-nos a ausência das estampas, as quais foram todas arrancadas pelos (as) usuários (as), possivelmente para tirar moldes para confecção de roupas da última moda. Nos folhetos, verificamos apenas dois títulos de entretenimento que podem ser considerados como de prosas de ficção, quais sejam: "Magnanimidade das Mulheres" (pp. 15-16) e "Sonho prodigioso" (pp. 28-30),

\footnotetext{
${ }^{7}$ Ernesto Rodrigues informa que, no mesmo ano, imprimia-se "O Armazém interessante, com estampas litografadas" que "inaugura entre nós [portugueses] o periodismo ilustrado" (RODRIGUES, 1998, p. 110).
}

seguidos por outras formas de entretenimento como a "Anedocta curiosa" (pp. 58-59) ou a "Extravagancia de hum Fidalgo" (p. 76).

Traçado um breve panorama, podemos dizer que mesmo antes que se findasse o primeiro quartel do século XIX, Portugal já dispunha de um bom número de periódicos em cujas folhas havia narrativas ficcionais impressas, o que nos faz supor alguns atores deste cenário. Redatores ou mesmo autoridades, como se viu no caso da Impressão Régia de Lisboa, esforçavam-se para inserir conhecimentos científicos e culturais no cotidiano das pessoas, por meio de publicações em jornais e revistas, veículos notoriamente de leitura mais leve que os tradicionais livros específicos. Entre tanta informação, por que não pensar que esses redatores e autoridades refletissem sobre a necessidade de incluir alguns escritos de recreio, talvez para minimizar o caráter instritivo de suas publicações?

É justo, ainda, imaginar o movimento de escritores ou tradutores portugueses interessados em publicar obras de teor ficcional, aproveitando a abertura concedida para tal e o crescimento do mercado editorial na área dos textos para deleite. Por fim, supomos um público leitor em formação, já conquistado por esses escritores e tradutores, à procura de momentos de prazer literário, de admiração estética, não somente proporcionado pelas narrativas disponíveis, mas também pelos poemas que volta e meia apareciam nos jornais e revistas.

Vale lembrar que os consumidores do mercado de periódicos não necessariamente eram alfabetizados, uma vez que poderiam ser leitores que apenas ouviam as histórias e 
notícias lidas por outrem. Além da baixa instrução formal, é consenso dizer que, com o passar do tempo, o aumento da concorrência e o consequente barateamento do preço das folhas, os leitores oitocentistas foram precisando dispor cada vez menos de recursos financeiros para desfrutar da cultura divulgada, socializar leituras, conhecer outras culturas pelas traduções, ou mesmo constituir coleções.

Comuns no século XIX, essas coleções eram feitas a partir do recorte e da encadernação manual, por meio da costura, das histórias ficcionais publicadas em pedaços nos jornais e poderiam representar um pequeno acervo bibliográfico doméstico, muitas vezes formado pela primeira vez entre as leitoras, sobretudo, como exemplifica Gina Guedes Rafael (2012, p. 37). A mesma autora atenta para o fato de que não somente pessoas iletradas e de baixa renda faziam parte do público-alvo dos periódicos do oitocentos, mas também os abastados e eruditos consumidores, que contribuíam com cartas e críticas para o andamento da redação dos próximos números. (Cf. RAFAEL, 2012)

Pode-se afirmar que houve ainda em princípios do século XIX narrativas ficcionais publicadas em Portugal, cuja relação, mesmo que coletados os títulos disponíveis, em suporte físico ou digital, dificilmente será completa. A Impressão Régia de Lisboa publicou um número considerável de romances, novelas e contos, quer em volumes individuais, quer em forma de artigos nos periódicos que imprimiu. Outros tipógrafos também souberam aproveitar o nicho de mercado que, aparentemente, se mostrava promissor. No intento de divulgar as narrativas ficcionais e o gênero romance, os periódicos tiveram importante papel, não somente pela própria impressão desses textos em suas páginas, como pelo anúncio dos livros disponíveis para aquisição no mercado livreiro local.

Com o tempo, o desenvolvimento da imprensa periódica em Portugal se dará de forma expressiva, como nos comprovam os números elencados por Ernesto Rodrigues:

O período de afirmação da Imprensa em Portugal acontece entre os anos de 1836 a 1840.

Os títulos publicados desde 1641 ditavam o seguinte quadro: até 1697 , três; de 1715 a 1800, 12; de 1801 a 1805, nove; no lustro seguinte, sob o influxo das invasões francesas, 26; 16 entre $1811 \mathrm{e}$ 1815; e 25 na véspera do movimento liberal.

A partir de 1821-1825, dá-se um salto cuja média pouco se altera até o termo da guerra civil: 61 novos jornais, 81 para 1826-1830 e recaída em 66 no período mais difícil de 1831-1835. (...)

No lapso de 1836 a 1840, saem 157 títulos (haveria $67 \mathrm{em}$ 1836, 59 no ano seguinte_, o que é notável, se compararmos com as quebras dos quinquénios seguintes: 77, 105, 108, 136. Só 25 anos depois, assistimos a retorna: 202 para 1861-65 e 201 entre 1866-1870. (RODRIGUES, 1998, pp. 95-96)

Como sabemos, em Portugal será na segunda metade do século XIX, sobretudo em período finissecular, que a expansão dos jornais e revistas e das práticas de impressão de histórias ficcionais até aqui descritas tomarão tão significativa força que já não será 
possível desconsiderá-las nos estudos literários. Contudo, nosso objetivo é conhecer como tudo começou.

\section{REFERÊNCIAS}

ABREU, M. Os caminhos dos Livros. Campinas. SP: Mercado de Letras, Associação de Leitura do Brasil (ALB); São Paulo: Fapesp, 2003.

ARAUJO, N. \& M., A. P. Aspectos da Tipografia em Portugal. Conferência realizada na Imprensa Nacional de Lisboa em 6 de abril de 1913. Lisboa: Imprensa Nacional, 1914.

BIBLIOTECA NACIONAL. Imprensa periódica portuguesa na metrópole e no império. Séculos XVII-XIX: edição comemorativa do tricentenário da publicação do primeiro periódico português. Lisboa: Biblioteca Nacional, 1941.

CANAVARRO, P. Bibliografia Sinóptica das obras impressas. In (Coord). Imprensa Nacional. Actividade de uma casa impressora. Vol. I 1768-1800. Lisboa: Imprensa Nacional Casa da Moeda, 1975. pp. 73-244.

GUEDES, F. O Livro e a Leitura em Portugal: Subsídios para a sua história. Séculos XVIII e XIX. Lisboa: Editorial Verbo, 1987.

HALLEWELL, L. O Livro no Brasil (sua história). (Trad.) Maria da Penha Villalobos e Lolio Lourenço de Oliveira. São Paulo: T. A. Queiroz/EDUSP, 1985.

PORTUGAL. Imprensa Nacional Casa da Moeda. Registo de obras impressas, liv. ${ }^{\circ} 6$ (1797-1803). Fundo 028 IN, Seção 2.2.13.1, Livro 481, Série contabilidade.

PORTUGAL. Arquivo Nacional da Torre do Tombo. Ministério do Reino. Registo de Cartas Régias e Alvarás para a Junta Economica, Administrativa e Literaria da Impressão
Régia. Livro 325. Decreto Real de 07 de Abril de 1769.

RAFAEL, G. G. Jornais, Romance-Folhetim e a leitura feminina no século XIX: influências transatlânticas?. Revista IRIS, Recife, v.1, n.1, jul./dez./2012. pp. 32-42. Disponível em: http:// www.repositorios.ufpe.br/revistas/index. php/IRIS/article/viewFile/9/7, consulta em 23/09/2015.

\& SANTOS, M. (org. e coord.). Jornais

e Revistas Portuguesas do séc. XIX. Lisboa: Biblioteca Nacional, 2001. 2 Vol.

RODRIGUES, E. Mágico Folhetim: Literatura e jornalismo em Portugal. Lisboa: Editorial Notícias, 1998.

SANT'ANNA, B. de C. L. Ilustração Brasileira (1854-1855) e a Ilustração Luso-Brasileira (1856, 1858, 1859): uma contribuição para o estudo da imprensa literária em Língua Portuguesa. São Paulo: [s.n.], 2007. Tese (doutorado) Universidade Estadual de São Paulo, Faculdade de Filosofia, Letras e Ciências Humanas.

SOUZA, S. C. M. de. Primeiras impressões: romances publicados pela Impressão Régia do Rio de Janeiro (1808-1822). Campinas, [s.n.], 2007. Tese (doutorado) - Universidade Estadual de Campinas, Instituto de Estudos da Linguagem.

TENGARRINHA, J. História da imprensa periódica portuguesa. Lisboa: Ed. Caminho, 1989.

THÉRENTY, M-È. O longo e o cotidiano. Sobre a dilatação midiática dos romances nos séculos XIX e XX. Trad. Pedro Paulo Garcia Ferreira Catharina. Interfaces, Rio de Janeiro, Número 22, Vol. 1, Janeiro-Junho 2015, pp. 117-136. Disponível em: http://www.cla.ufri.br/images/ docs/interfaces/split/22/08_o\%2olongo\%20 e\%cotidiano.pdf, consulta em 30/09/2015. 
VASCONCELOS, S. G. T. Dez lições sobre o romance inglês do século XVIII. São Paulo: Boitempo Editorial, 2002.

VELOSO, L. M. M. Elementos para a história da imprensa periódica portuguesa. In SOUZA, J. M. de. \& VELOSO, L. M. M. Historia da imprensa periódica portuguesa: subsídios para uma bibliografia. Coimbra: Coimbra Editora, 1987.

WATT, I. A ascensão do romance: Estudos sobre Defoe, Richardson e Fielding. Trad. Hisdegard Feist. São Paulo: Companhia das Letras, 1990.

\section{Periódicos}

Analecto de Recreação e erudição. Por **** Numero I. Lisboa, na Impressão Regia. M.DCCC.V. Por Ordem Superior. (Biblioteca Nacional de Portugal. P.P.7314 P)

Armazem interessante e recreativo ou collecção de novellas, e noticias uteis, e agradaveis. N. I. Lisboa. MDCCCVI. Na Impressão de Bernardo José Alcobia. Com licença da Meza do desembargo do Paço. (Biblioteca Nacional de Portugal. L. 6590 1 P)

Bibliotheca Universal extrahida de muitos jornaes, e das obras dos melhores escritores Antigos, e modernos. Pelo author das Viagens de Altina. Lisboa. M.DCCCIII. Na Offic. deThaddeo Ferreira, Com licença da Meza do Desembargo do Paço. (Biblioteca Nacional de Portugal. F.2578; F.2479 e J. 1)

Divertimento Instructivo ou Collecção escolhida de novellas, historias, contos moraes, anedoctas interessantes, paravolas, fabulas, ditos filosoficos, contos para rir, \&c. Obra moral, instructiva, e agradavel destinada para honesto divertimento, e util instrucção da mocidade Portugueza. N. I. Lisboa: Na Impressão Regia. Anno de M.D.CCC.IV. Por
Ordem Superior. (Biblioteca Nacional de Portugal. P. 3509 I P)

Gazeta de Lisboa. Microfilme. (Biblioteca Nacional de Portugal. J 2510 M)

O Redactor ou ensaios periodicos de litteratura, e conhecimentos scientificos destinados para illustrar a Nação Portugueza. 1803. Lisboa. Na Impressão Regia. Por Ordem Superior. (Biblioteca Nacional de Portugal. J. 1306 B B B) Variedades: publicação literaria, compreendendo historia geral, anedotas.... Numero XIII, Volume III. Lisboa. MDCCCII. Na Off, de Simão Theddeo Ferreira. Com licença da Meza do Defembargo do Paço. (Biblioteca Nacional de Portugal. P. 286 P)

Recebido para publicação em 10 out. 2015 Aceito para publicação em o1 dez. 2015. 